\title{
30. The concept of simultaneous feedback
}

1. Simultaneous feedback (SF)

2. From SF to fuzzy SF

3. From fuzzy SF to modern dictionary research

4. From modern dictionary research to open questions

5. Selected bibliography

\section{Simultaneous feedback (SF)}

The theoretical concept of simultaneous feedback (henceforth 'SF'), introduced in 1997 and described in De Schryver's (1999b) MA dissertation, was devised in response to the need for a framework for the swift yet sound compilation of Bantu-language dictionaries. Since then, it has been applied to the compilation of numerous reference works across the world. In a nutshell, and as initially conceived, SF can be understood as entailing a dictionary-making method in terms of which the release of several small-scale parallel dictionaries triggers off feedback that is instantly channelled back into the compilation process of a main dictionary. This process is shown schematically in Tab. 30.1.

In this representation, one recognises the three primary constituents of any dictionary compilation process, viz. target users, compilers and dictionaries. The framework itself should be read from left to right, and from top to bottom - [1] through [10]. The compilers' central task is the compilation of a main dictionary - depicted by the central, downward arrow. The first component in Tab. 30.1 is also the first task. That is, the formulation of a theoretically motivated model for the structure and contents of the dictionary to be compiled, must be followed by a preliminary analysis of the desires of the potential target users - [1]. It is of paramount importance that, from this initial stage onwards, information concerning these target users' desires be gathered through informal and formal consultations with the future target users. As such, feedback is simultaneously introduced right from the very start. Since any modern dictionary is to derive its data from a corpus, the compilers have to build and query an electronic corpus for the specific language(s) 'first'. As a result, the compilers cannot start the compilation of the main dictionary right away and are moreover confronted with the prospect of an ex- tremely time-consuming undertaking. In order to overcome this deadlock, the main dictionary project is instantly complemented with a series of small and inexpensive parallel dictionary projects - [2], [6], [10], etc. These parallel projects have basically the same structure, contents and target users as the main project and are to derive their data from small-scale parallel test-corpora. From the release of the first parallel dictionary onwards, informal and formal feedback is received from the parallel projects and channelled back into the time-consuming main project - [3], [7], etc. From that instant, the compilation of the main dictionary becomes a true work in progress with simultaneous feedback from the target users to the compilers. The parallel projects are thus used as experimental tools to test a plethora of strategies in order to refine both the information and the presentation thereof in the main project under construction. Once a structured main corpus has been built, various frequency studies can be undertaken to assist the lexicographers in the compilation of the lemma-sign list of the main dictionary - [4]. Subsequently, concordance lines, also derived from the main corpus, supplement the compilers' intuition during the compilation of the main dictionary articles - [8]. Until completion of the main project the parallel projects continue to elicit feedback - [5], [9], etc. All this simultaneous feedback ultimately enables the compilers to select the most appropriate blend of lexicographic procedures to ensure the most effective retrieval of information by the target users in the main dictionary. It is important to stress the fact that the target users guide the compilers near-simultaneously during the entire compilation process. The unabated retrieval of feedback should thus be considered as the main pillar of the methodology.

Early bilingual (parallel) dictionaries compiled within this framework include reference works for Cilubà (De Schryver/Kabuta 1997/ 1998; De Schryver 1999a: 55-87) and Northern Sotho (Prinsloo/De Schryver 2000; De Schryver 2001). Currently, and as another example, all eleven South African National Lexicography Units periodically release parallel dictionaries within this framework, and this approach is also followed in Gabon (Ma- 


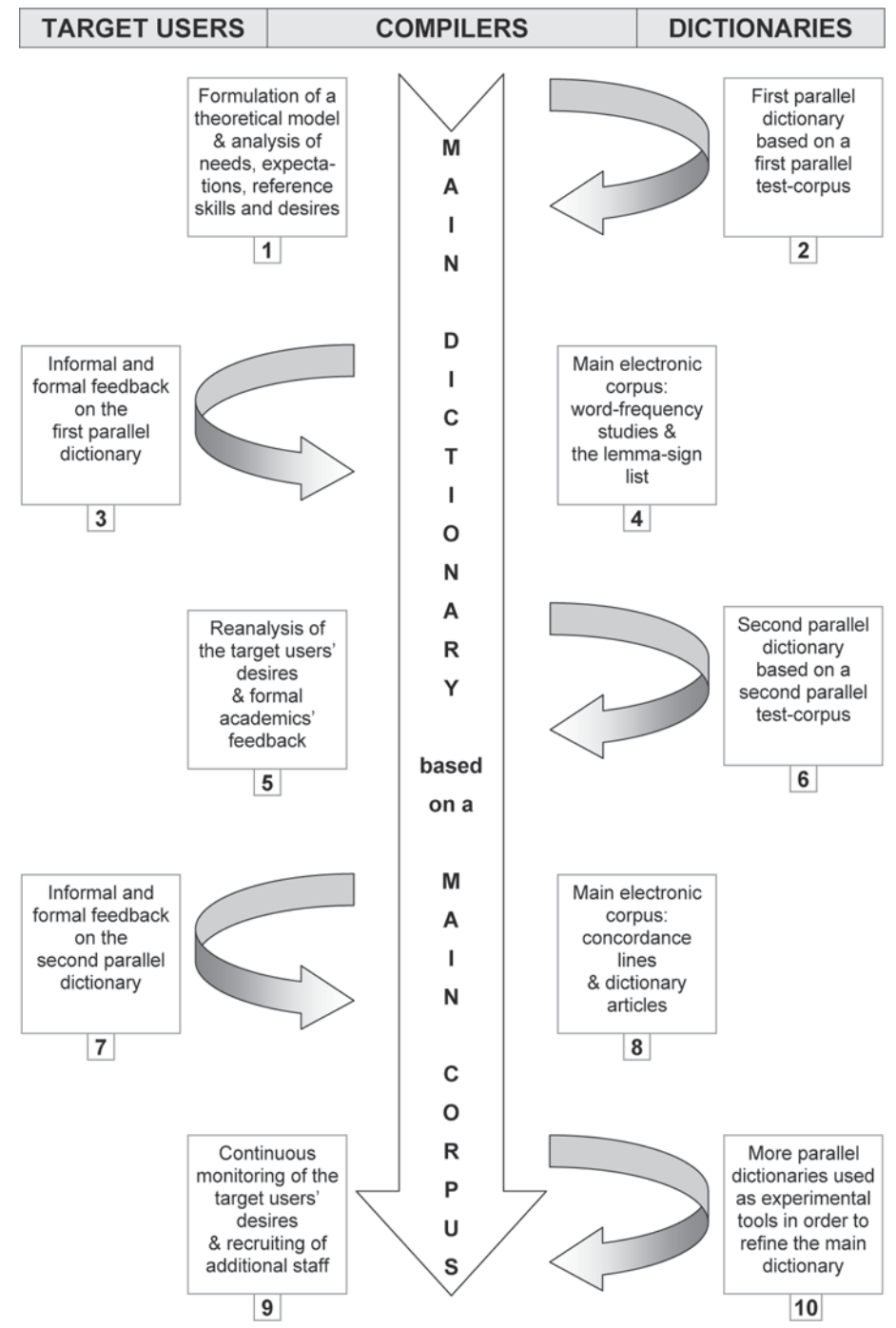

Tab. 30.1

voungou 2002). For article-length descriptions of all aspects involved, see De Schryver/ Prinsloo $(2000 \mathrm{a} / \mathrm{b})$.

\section{From SF to fuzzy SF}

In the Cilubà and Northern Sotho projects referred to in section 1, the retrieval of feedback has followed the channels of such standard approaches as (natural) participant observation, formal and informal discussions, anonymous mail survey questionnaires, controlled tests, etc. Through a cross-comparison of the results of the various types of feedback, the idea has been to arrive at a repre- sentative body of users' desires for each of the respective target user groups. Still, the realisation that none of the employed feedback methods is devoid of problems, and that even the balancing out of different types of feedback is only approximate, prompted the search for a straightforward, automatic, neutral and invisible arbiter. Such an unobtrusive arbiter was found in the form of electronic-dictionary $\log$ files. In other words, instead of compiling various parallel hardcopy dictionaries (blocks [2], [6], [10], etc. in Tab. 30.1) for the purposes of retrieving feedback (blocks [3], [7], etc.) - feedback that is instantly fed back into the compilation 
of a main dictionary - the idea is to make the dictionary available online on the Internet while it is still being compiled, and thus to be able to log and use feedback truly simultaneously. With this one has arrived at a bold compilation strategy indeed, as users are not only invited to be spectators of 'in progress dictionary compilation', but are also, implicitly and informally, led to provide crucial feedback while using that in-progress work. From a dictionary-compilation strategy angle one has thus moved from a discrete approach to retrieving feedback for a group of users to a continuous one for single users, which is why the 'electronic adaptation' of SF has been baptised 'Fuzzy SF'. In addition, fuzzy SF allows for (in-progress) dictionaries to be made continually available, and this from the moment work on them has begun. Fuzzy SF thus enables to have 'dictionaries now'. A dictionary compiled within the framework of fuzzy SF is known as a 'Fuzzy SF dictionary'.

Compared to any principle currently utilised in dictionary-making and compared to any existing multimedia reference work, the following ten key novelties of fuzzy SF are either absent from or would constitute important improvements over what is done or available at present (for a full description, see De Schryver/Prinsloo 2001):

(1) In addition to data being continuously available online, parallel packages (both in print or in electronic format) may be released throughout the endeavour to compile a main package, answering an urgent desideratum to provide users with dictionaries now, and enabling the inclusion of feedback into the very compilation methodology itself.

(2) Since a completed package has been thoroughly 'tested' before it is released, it contains user feedback right from the start; and once it is used it (preferably) gathers its feedback indirectly, informally and unknowingly, eliminating any barriers between compilers and users.

(3) The package offers fully fledged default dictionaries, just like any other hardcopy or electronic dictionary, and, additionally, each user can retrieve a personally tailored reference work in print or in electronic format.

(4) The package is a family reference work that can be customised for several users, and is continuously re-customised for each single user over time.

(5) The package is primarily descriptive, and includes tools for user-initiated modifications.

(6) The package provides for all linguistically sound lemmatisation approaches in parallel, allowing users to decide on the one(s) appropriate for them at the time of consultation.

(7) Both the access to and the visual presentation of the data slots are such that the distinction between onomasiological and semasiological dictionaries tends to disappear.

(8) The package endeavours to be all dictionaries in one, moulding itself according to specific needs and varying with time as a decoding or encoding, monolingual, bilingual or hybrid dictionary, with adjustable/graded difficulty levels.

(9) The package contains a set of fully integrated built-in multimedia (sub)corpora (i.e. text, computer graphics and audio), from which data are generated automatically when needed (i.e. are queried unperceivingly by the software), and which can also be accessed interactively (i.e. are queried knowingly by the users).

(10) Finally, all multimedia data slots - whether they have been prepared by the lexicographers, have been culled automatically or interactively from the sub(corpora), or have been supplemented/supplied by the user - are hyperlinked in the package on all levels and in all directions.

In retrospect, a fuzzy SF dictionary puts into practice quite a number of Abate's (1985) and Dodd's (1989) far-sighted suggestions for the electronic dictionary of the future. In addition, of all prototype electronic dictionaries proposed in the 1990s, a fuzzy SF dictionary comes closest to Atkins' (1996) 'virtual dictionary'. Yet, whereas the latter is mainly created at the time of dictionary consultation, fuzzy SF aims to build a true user profile, through the continuous retrieval of feedback, with which a tailored reference work is simultaneously assembled.

Not surprisingly, the compilation of the latest Cilubà and Northern Sotho dictionaries proceeds within the framework of fuzzy SF, see Kabuta et al. (2006) and De Schryver/ Joffe (2003) respectively. As another known and acknowledged example of dictionary compilation within the framework of (fuzzy) $\mathrm{SF}$, in Slovenia a hypertext dictionary of Japanese lexical units for Slovene students of Japanese is being developed in real time on the Internet (Hmeljak Sangawa 2002; Erjavec et al. 2003/2004).

\section{From fuzzy SF to modern dictionary research}

In implementing fuzzy SF, one is not only confirming the feasibility of fuzzy SF as a dictionary compilation methodology, nor just 


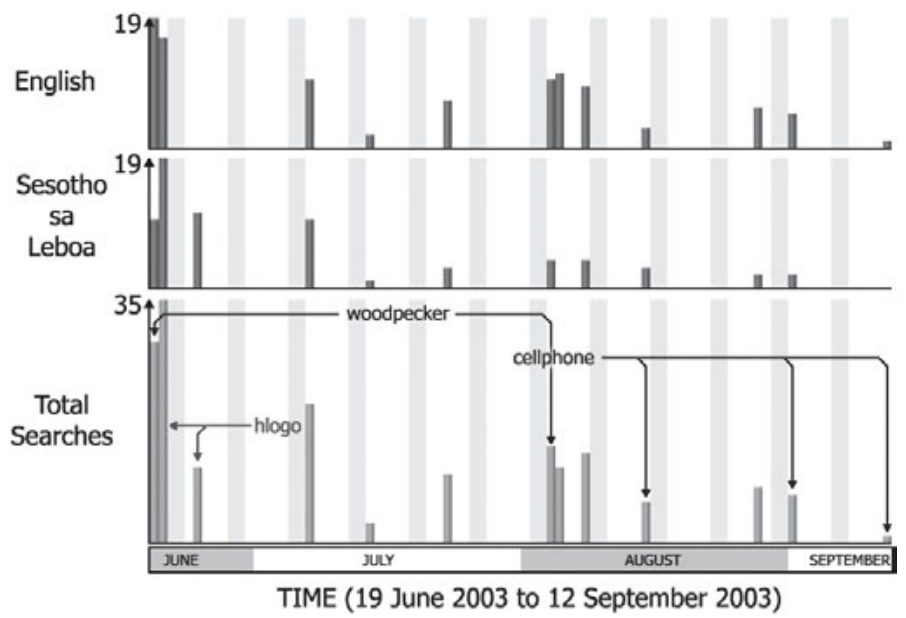

Tab. 30.2

providing dictionaries now, but in reality also undertaking modern dictionary research in addition. In the present section fuzzy SF will be approached from the latter angle.

Although the proposal to draw upon log files in order to improve dictionaries was already expressed in the mid-1980s (Abate 1985; Crystal 1986), and although numerous researchers have reiterated this idea in recent years (Hulstijn/Atkins 1998; Sobkowiak 1999; Docherty 2000; Harley 2000; Sato 2000; Pruvost 2003; Varantola 2003), very few reports have been published of realworld dictionaries actually making use of this strategy. Notable exceptions are Löfberg (2002), Prószéky/Kis (2002), Jakopin/Lönneker (2004) and Bergenholtz/Johnsen (2005). Instead, electronic dictionaries cum log files seem to be more popular in research environments focusing on vocabulary acquisition (e.g. Hulstijn 1993; Knight 1994; Hulstijn/ Trompetter 1998; Laufer 2000; Laufer/Hill 2000). When it comes to electronic dictionaries, statements regarding log files are often hypothetical, such as in: "A log file of user access and queries is kept that should serve to give insight on how such a service is used" (Popescu-Belis et al. 2002: 1144 [emphasis added]). What is true for log files, is also true for the utilisation of direct feedback, whereby users are encouraged to comment online (Dodd 1989; Carr 1997; Considine 1998; Harley 2000; Nesi 2000; Warburton 2000; Campoy Cubillo 2004; Ne'eman/Finkel 2004); that is, reports on what is done with this type of feedback are hard to come by.
One of the earliest implementations of (the first stages of) a fuzzy SF dictionary on the Internet was for the Online Northern Sotho - English Dictionary (De Schryver/Joffe 2003). Of the five novelties introduced in that reference work (cf. De Schryver 2003: 5-10), one is highly relevant here, namely the socalled 'dynamic metalanguage customisation'. This means that, depending on the interface-language chosen, the output-language of all metalanguage such as POS tags, usage labels, cross-reference marker texts, etc. is customised. A world's first for any online dictionary at the time (and to this date), this metalanguage customisation is realised in real time and thus dynamically on the Internet, and as such this was a first (timid) step towards a true fuzzy SF dictionary.

An article-length analysis of the log files attached to this dictionary, as well as of the online feedback forms, may be found in De Schryver/Joffe (2004). Of notable importance are the unobtrusive studies of dictionary look-up behaviour for particular users. In Tab. 30.2, for instance, some of the searches made by one of the many regular visitors, here between 19 June and 12 September 2003, are shown.

During the studied period this visitor performed 168 searches, looked up in both Northern Sotho and English, and did not use the dictionary on weekends (grey). The word hlogo 'head; prefix; heading; principal' being rather polysemous, it is not surprising it was looked for repeatedly; yet the two searches for 'woodpecker' suggest that there was no 
long-term retention for the ways to express this word in Northern Sotho. The data also indicate that users seem to take the compilers - and with this perhaps even fuzzy SF seriously. In Tab. 30.2, the first search for 'cellphone' (on August 15) was unsuccessful. During this user's next visit (on August 28), the feedback form was filled in with a request that the compilers come up with a translation equivalent for this word. Already four days later (on September 1) this user checked again, yet the matter was still being researched. Three days later an acceptable translation (mogalathekeng) was found and uploaded. A third search for 'cellphone' (on September 12) then returned a hit. Note, in passing, that a fuzzy SF dictionary may thus also be viewed as a service to the community.

This brief presentation of the Online Northern Sotho - English Dictionary - lest it be forgotten, a real electronic dictionary used in a natural setting with no manipulation of research variables whatsoever shows that with the discussed tracking function, any number of individual user's look-up strategies may be monitored over time, which is especially relevant for studying vocabulary retention and for drawing up user profiles needed for an intelligent and adaptive fuzzy SF dictionary. Generalisable user profiles are indeed becoming visible, although formalising these remains to be done for this dictionary. As far as fuzzy SF as a dictionary compilation methodology is concerned, the very fact that an in-progress dictionary is available and is used (while still being compiled) indicates that the approach is feasible. Revisions and improvements of an online dictionary may indeed successfully be based on a semiautomatic analysis of log files, in combination with follow-ups on feedback received electronically.

\section{From modern dictionary research to open questions}

While the research results presented in section 3 indicate that unique user profiles can indeed be drawn up with which tailored dictionary data may then be presented to those users, there are also aspects of dictionary look-up behaviour which seem not to be predictable (cf. De Schryver et al. 2006). In this section, a few of these are highlighted, using some of the log-file statistics attached to the Online Swahili - English Dictionary (Hille-

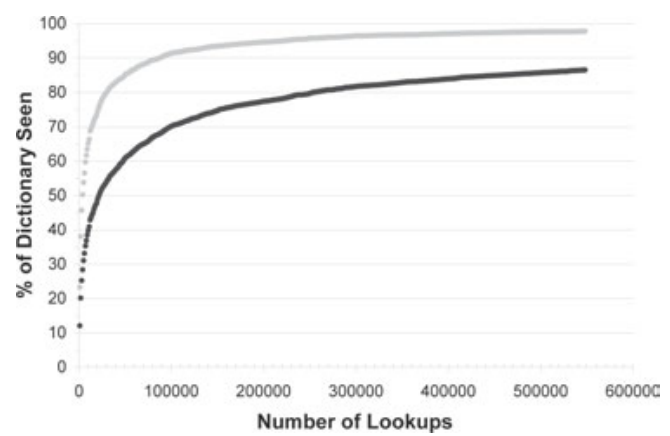

Tab. 30.3

waert/De Schryver 2004), for which a good amount of data is available.

With regard to online dictionaries, the metalexicographers Bergenholtz and Johnsen (2005: 122) boldly wondered: "Will all lemmas in the dictionary be looked up in time when the dictionary has had many more users? Or are there some lemmas that will never be looked up? If future dictionary makers knew the answers to those questions, they would not have to waste time describing words of no interest to the users." Are there indeed lemmas that are of no interest to anyone? To test this hypothesis, the first half a million searches logged for the Online Swahili - English Dictionary may be looked at in order to see which percentage of the dictionary is being returned as the number of searches grows over time. Taking a snapshot every one thousand searches, the graph shown in Tab. 30.3 is obtained.

The bottom curve indicates that over $86 \%$ of the material has been searched for directly, while the top curve indicates that close to $98 \%$ of the dictionary data have been returned when one also includes the cross-referenced material (which is shown on the same output page for this dictionary). Looking at the trend of these curves, it should be clear that all dictionary data will indeed be seen over time. This thus means that there is no shortcut to dictionary compilation here, as all data are indeed being looked up at some point in time.

The next logical question is whether there are perhaps lemmas that are more likely to be looked up than others. With over half a million dictionary searches at one's disposal on the one hand, and with corpus-derived frequencies on the other, it becomes possible to calculate various correlation coefficients 


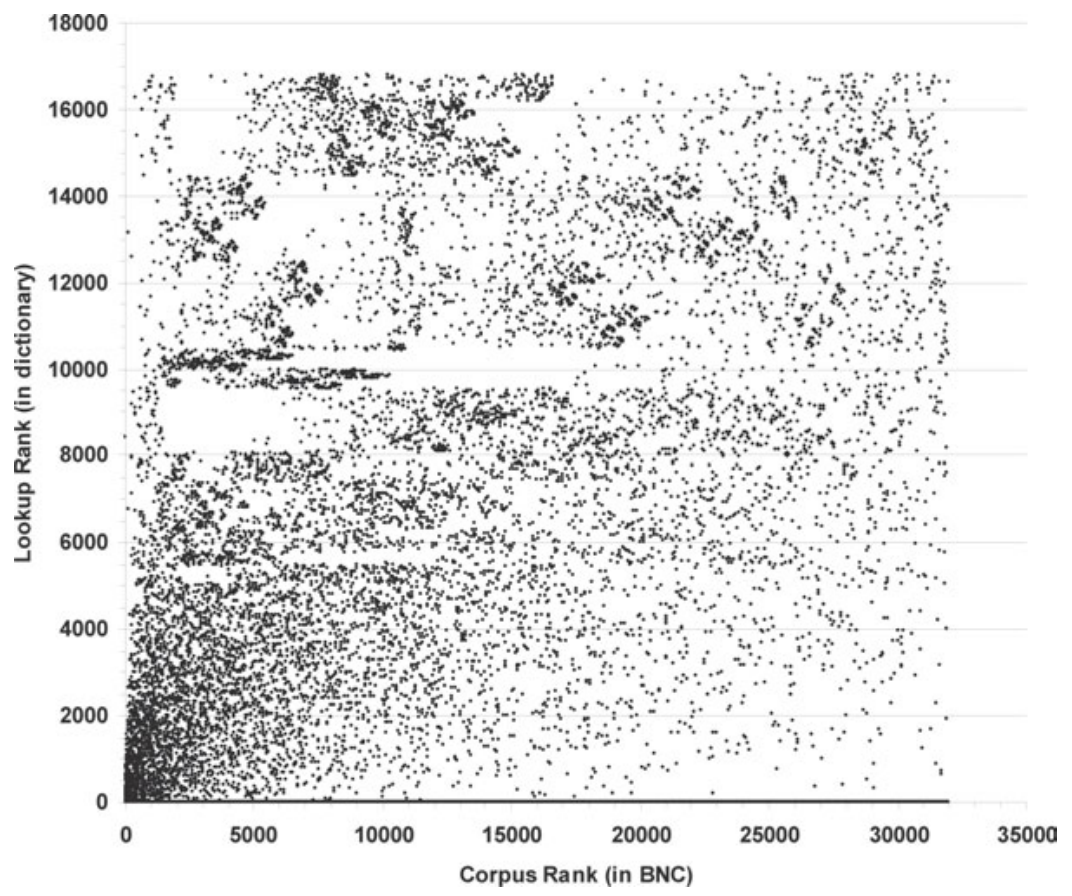

Tab. 30.4

between the two sets of data. Reformulated, one can effectively take a list of corpus words, and compare that list word for word with actual dictionary searches, and/or one can take searched-for items in a dictionary, and compare those with the corpus. There are different ways to approach this question, but one of the most straightforward ones is as follows. In a two-dimensional plane one could plot the corpus data (as frequencies or ranks) on one axis, and the corresponding actual dictionary lookups (expressed as a count or also as a rank) on the other axis. If corpusbased lexicography indeed reflects (or rather 'pre-empts') what users look up (or 'will look up') in a real dictionary, then the most frequent word in the corpus should also correspond with the word most frequently searched for, the tenth most frequent corpus item should correspond with the tenth most frequent lookup, the one hundredth with the one hundredth, etc. In this ideal situation, the result would be a straight line out of the intersection of the axes in the two-dimensional plane. Allowing for (small) deviations, the straight line would turn into a 'scatter plot', with a cloud of dots 'around' the imaginary straight line. Mathematically, the straight line corresponds with a Pearson correlation coef- ficient of 1.0, while deviations result in lower values. The actual scatter plot for English is shown in Tab. 30.4, where each dot represents the dictionary lookup rank of a particular word versus the corpus rank for that word in the BNC (British National Corpus).

If one zooms in on the area around the intersection of the axes in Tab. 30.4, or thus the top ranks, then one does see some kind of vague correlation (of around 0.2 ), but as one moves along the axes, this correlation vanishes entirely. Therefore, while there is indeed some minor correlation between corpus ranks and actual dictionary lookup ranks for the first few thousand words (up to around rank 5,000 for English in this online dictionary), beyond that point there simply is no correlation whatsoever.

This is a hugely important - albeit shocking - revelation, as it looks as if it is simply impossible to 'predict' which words will be of interest to the dictionary user. To make this conclusion more tangible, take for example Tab. 30.4 at the BNC rank 15,000, which could be the cut-off point for a dictionary with an upper limit of roughly fifteen thousand entries. Looking upwards from that point in Tab. 30.4, it should be clear that it is unfortunately so that virtually any word may 
be looked up with any frequency at this cutoff point.

According to the computational linguist Adam Kilgarriff, however, it is still possible to predict what users will need: "They'll tend to look up the contentious ones, the ones that are hard to spell, the ones with odd origins, obviously the rude ones. There's no obvious relation between these factors and frequency, but why should there be?" and he further suggests: "One would start expecting the correlation to become serious much further along the frequency range - words after 200,000 in the corpus (and hence well outside most speakers' experience) receiving fewer lookups than words before." (Kilgarriff 2006, personal communication). Clearly, one would need much more evidence, and thus much more data, to properly study these hypotheses. As such, this, for now, remains unresolved, and is an open invitation for other researchers to join the research.

One of the exciting developments in present-day lexicography revolves around electronic dictionaries in which the potential is explored to link an automatically derived dynamic user profile to the proffered multimedia lexicographic output. As a product, such (adaptive) dictionaries were referred to as fuzzy SF dictionaries. However, fuzzy SF is also a new approach to compiling dictionaries, given that it is the electronic adaptation of the dictionary-compilation methodology known as simultaneous feedback. A fuzzy SF dictionary as a product, then, is first compiled within the framework of fuzzy SF. A fuzzy SF dictionary is furthermore - by design - an excellent tool to study genuine dictionary use, which in turn leads to exciting answers to age-old as well as new lexicographic questions.

\section{Selected bibliography}

\subsection{Printed dictionaries}

De Schryver, G.-M. (ed.) (2001): Pukuntšutlhaloši ya Sesotho sa Leboa 1.0 (PyaSsaL's First Parallel Dictionary). Pretoria.

De Schryver, G.-M./Kabuta, N. S. (1997): Lexicon Cilubà - Nederlands, Een circa 2500-lemma's-tellend strikt alfabetisch geordend vertalend aanleerderslexicon met decodeer-functie ten behoeve van studenten Afrikaanse Talen \& Culturen aan de Universiteit Gent. Ghent.

De Schryver, G.-M./Kabuta, N. S. (1998): Beknopt woordenboek Cilubà - Nederlands \& Kalombodi- mfùndilu kàà Cilubà (Spellingsgids Cilubà), Een op gebruiks-frequentie gebaseerd vertalend aanleerderslexicon met decodeerfunctie bestaande uit circa 3.000 strikt alfabetisch geordende lemma's \& Mfùndilu wa myakù ìdì itàmba kumwèneka (De orthografie van de meest gangbare woorden). Ghent.

Prinsloo, D. J./De Schryver, G.-M. (eds.) (2000): SeDiPro 1.0, First Parallel Dictionary Sepêdi English. Pretoria.

\subsection{Electronic dictionaries}

De Schryver, G.-M./Joffe, D. (2003): Online Sesotho sa Leboa (Northern Sotho)-English Dictionary. Available: http://africanlanguages.com/sdp/

Hillewaert, S./De Schryver, G.-M. (2004): Kamusi ya Kiswahili-Kiingereza Katika Mtandao / Online Swahili-English Dictionary. Available: http:// africanlanguages.com/swahili/

Kabuta, N. S. et al. (2006): Nkòngamyakù wa Cilubà-Mfwàlànsa / Dictionnaire Cilubà-Français. Available: http://www.ciyem.ugent.be/

\subsection{Other references}

Abate, F. R. (1985): Dictionaries Past \& Future: Issues and Prospects. In: Dictionaries 7, 270-283.

Atkins, B. T. S. (1996): Bilingual Dictionaries: Past, Present and Future. In: Gellerstam, M. et al. (eds.), Euralex '96 Proceedings. Gothenburg, 515-546.

Bergenholtz, H./Johnsen, M. (2005): Log Files as a Tool for Improving Internet Dictionaries. In: Hermes 34, 117-141.

Campoy Cubillo, M. C. (2004): Computer-mediated lexicography: An insight into online dictionaries. In: Campoy Cubillo, M. C./Safont Jordà, P. (eds.), Computer-Mediated Lexicography in the Foreign Language Learning Context. Castelló de la Plana, 47-72.

Carr, M. (1997): Internet Dictionaries and Lexicography. In: International Journal of Lexicography 10,3, 209-230.

Considine, J. P. (1998): Why do large historical dictionaries give so much pleasure to their owners and users? In: Fontenelle, T. et al. (eds.), Euralex '98 Proceedings. Liège, 579-587.

Crystal, D. (1986): The ideal dictionary, lexicographer and user. In: Ilson, R. F. (ed.), Lexicography: An emerging international profession. Manchester, $72-81$.

De Schryver, G.-M. (1999a): Cilubà Phonetics, Proposals for a 'corpus-based phonetics from below'-approach. Ghent.

De Schryver, G.-M. (1999b): Bantu Lexicography and the Concept of Simultaneous Feedback, Some 
preliminary observations on the introduction of a new methodology for the compilation of dictionaries with special reference to a bilingual learner's dictionary Cilubà - Dutch. MA Dissertation. Ghent University.

De Schryver, G.-M. (2003): Online Dictionaries on the Internet: An Overview for the African Languages. In: Lexikos 13, 1-20.

De Schryver, G.-M./Joffe, D. (2004): On How Electronic Dictionaries are Really Used. In: Williams, G./Vessier, S. (eds.), 187-196.

De Schryver, G.-M./Joffe, D./Joffe, P./Hillewaert, S. (2006): Do Dictionary Users Really Look Up Frequent Words? - On the Overestimation of the Value of Corpus-based Lexicography. In: Lexikos $16,67-83$.

De Schryver, G.-M./Prinsloo, D. J. (2000a): Dictionary-Making Process with 'Simultaneous Feedback' from the Target Users to the Compilers. In: Heid, U. et al. (eds.), 197-209.

De Schryver, G.-M./Prinsloo, D. J. (2000b): The Concept of 'Simultaneous Feedback': Towards a New Methodology for Compiling Dictionaries. In: Lexikos 10, 1-31.

De Schryver, G.-M./Prinsloo, D. J. (2001): Fuzzy SF: Towards the ultimate customised dictionary. In: Studies in Lexicography 11,1, 97-111.

Docherty, V. J. (2000): Dictionaries on the Internet: An Overview. In: Heid, U. et al. (eds.), $67-74$.

Dodd, W. S. (1989): Lexicomputing and the dictionary of the future. In: James, G. C. A. (ed.), Lexicographers and Their Works. Exeter, 83-93.

Erjavec, T./Hmeljak Sangawa, K./Srdanović, I. (2003): An XML TEI Encoding of a Japanese-Slovene Learners' Dictionary. In: Proceedings B of IS 2003. Ljubljana, 20-24.

Erjavec, T./Hmeljak Sangawa, K./Srdanović, I/ Vahčič, A. M. (2004): Making an XML-based Japanese-Slovene Learners' Dictionary. In: Proceedings of LREC 2004. Lisbon, 1059-1062.

Harley, A. (2000): Cambridge Dictionaries Online. In: Heid, U. et al. (eds.), 85-88.

Heid, U. et al. (eds.) (2000): Euralex 2000 Proceedings. Stuttgart.

Hmeljak Sangawa, K. (2002): Slovar japonskega jezika za slovenske študente japonščine [A Japanese Dictionary for Slovene Students of Japanese]. In: Proceedings of SDJT 2002. Ljubljana, 102105.

Hulstijn, J. H. (1993): When do foreign-language readers look up the meaning of unfamiliar words?
The influence of task and learner variables. In: The Modern Language Journal 77,2, 139-147.

Hulstijn, J. H./Atkins, B. T. S. (1998): Empirical research on dictionary use in foreign-language learning: survey and discussion. In: Atkins, B. T. S. (ed.), Using Dictionaries: Studies of Dictionary Use by Language Learners and Translators. Tübingen, 7-19.

Hulstijn, J. H./Trompetter, P. (1998): Incidental learning of second language vocabulary in computer-assisted reading and writing tasks. In: Albrechtsen, D. et al. (eds.), Perspectives on Foreign and Second Language Pedagogy: Essays Presented to Kirsten Haastrup on the Occasion of her Sixtieth Birthday. Odense, 191-200.

Jakopin, P./Lönneker, B. (2004): Query-driven Dictionary Enhancement. In: Williams, G./Vessier, S. (eds.), 273-284.

Knight, S. (1994): Dictionary use while reading: The effects on comprehension and vocabulary acquisition for students of different verbal abilities. In: The Modern Language Journal 78,3, 285-299.

Laufer, B. (2000): Electronic dictionaries and incidental vocabulary acquisition: does technology make a difference? In: Heid, U. et al. (eds.), 849854.

Laufer, B./Hill, M. (2000): What Lexical Information do L2 Learners Select in a Call Dictionary and How Does it Affect Word Retention? In: Language Learning \& Technology 3,2, 58-76.

Löfberg, L. (2002): Miksi sanat eivät löydy sanakirjasta? Tapaustutkimus MOT Englanti 4.0. MA Dissertation. University of Tampere.

Mavoungou, P. A. (2002): Synopsis Articles in the Planning of a Trilingual Dictionary: YilumbuFrench-English. In: Lexikos 12, 181-200.

Ne'eman, Y./Finkel, R. (2004): Rav-Milim Online. In: Kernerman Dictionary News 12, 28-31.

Nesi, H. (2000): Electronic Dictionaries in Second Language Vocabulary Comprehension and Acquisition: The State of the Art. In: Heid, U. et al. (eds.), 839-847.

Popescu-Belis, A./Armstrong, S./Robert, G. (2002): Electronic Dictionaries - from Publisher Data to a Distribution Server: The DicoPro, DicoEast and RERO Projects. In: Proceedings of LREC 2002. Las Palmas, 1144-1149.

Prószéky, G./Kis, B. (2002): Development of a Context-Sensitive Electronic Dictionary. In: Braasch, A./Povlsen, C. (eds.), Euralex 2002 Proceedings. Copenhagen, 281-290.

Pruvost, J. (2003): Some Lexicographic Concepts Stemming from a French Training in Lexicology (1). In: Kernerman Dictionary News 11, 10-15. 
Sato, H. (2000): Multi-Functional Software for Electronic Dictionaries. In: Heid, U. et al. (eds.), $863-870$.

Sobkowiak, W. (1999): Pronunciation in EFL Machine-Readable Dictionaries. Poznań.

Varantola, K. (2003): Linguistic corpora (databases) and the compilation of dictionaries. In: Van Sterkenburg, P. (ed.), A Practical Guide to Lexicography. Amsterdam, 228-239.
Warburton, Y. (2000): The Oxford English Dictionary - From OED to OED Online. In: International Journal of Lexicography 13,2, EURALEX Newsletter, 7-8.

Williams, G./Vessier, S. (eds.) (2004): Euralex 2004 Proceedings. Lorient.

Gilles-Maurice de Schryver, Ghent University (Belgium) \& University of the Western Cape (South Africa)

\section{User research in the field of electronic dictionaries: Methods, first results, proposals}

1. User surveys

2. Better dictionaries through the use of $\log$ files

3. Log files, corpus-based lemma selection and search options

4. Comparative surveys and the status of the lemma

5. Suggested structure of log files for Internet dictionaries and the use of outside matter

6. First experiments with function-oriented log files

7. Proposals

8. Selected bibliography

\section{User surveys}

In 1997, Wiegand called attention to "a remarkable research lacuna" (Wiegand 1977: $62 \mathrm{f}$.). He was referring to the complete lack of interest in the dictionary user which is and was attributable to the fact that many lexicographers do not perceive dictionaries as a tool to help people with text reception, text production, translation or the attainment of knowledge about specific or general linguistic or encyclopaedic issues. His call was widely heeded and marked the beginning of the process that may lead lexicography away from a lexicographic practice consisting of linguistic descriptions towards a different practice where dictionaries are viewed as tools. Wiegand also called for empirically based user sociology. It is commonly believed that this conception of lexicography is generally accepted and that Wiegand's demands have already been met. We do not share this optimism. At least 600 papers and books concerning so-called user surveys (Welker 2006 provides an overview) have been pub- lished. These user surveys are characterised by the fact that the great majority do not even come close to meeting the two basic requirements for surveys as defined in social science:

(1) A scientifically valid survey must be based on a sample of the target population that is statistically representative of the entire population.

(2) The respondents must be selected by the researcher on the basis of principle (1).

Thus, the respondents cannot select themselves by answering an open survey in which everyone is allowed to participate. Furthermore, the researcher cannot use as respondents a select group of people that s/he happens to have easy access to, e.g. a particular group of university students that the researcher teaches.

None of the available surveys adhere to both principles (in this context, other types of user surveys not intended to provide a representative description of user behavior in various types of experiments (e.g. Tono 2001) or case studies (e.g. Bergenholtz 2009 and Bergenholtz/Gouws 2010) are disregarded). The respondents are selected according to the principle of 'who will be easiest to ask?'. The respondents, usually between 20 and 100 people, are thus not representative of a particular population. What is even worse is that the questions are strangely irrelevant and memory-based: 'How often do you use a dictionary? Every day? Once a week?', etc. They may also pertain to future use of dictionaries: 'What would be particularly important to you if you were to use a dictionary? Defini- 